\title{
Characterization and Identification of Phytate Solubilizing Yeasts Isolated from Food Grains
}

\author{
P.D. Savita ${ }^{*}$, V.C. Suvarna, T. Annu, A.N. Balakrishna, B. Kanchanashri and M. Yallappa \\ Department of Agricultural Microbiology, University of Agricultural Sciences, \\ GKVK, Bangalore, Karnataka, India \\ *Corresponding author:
}

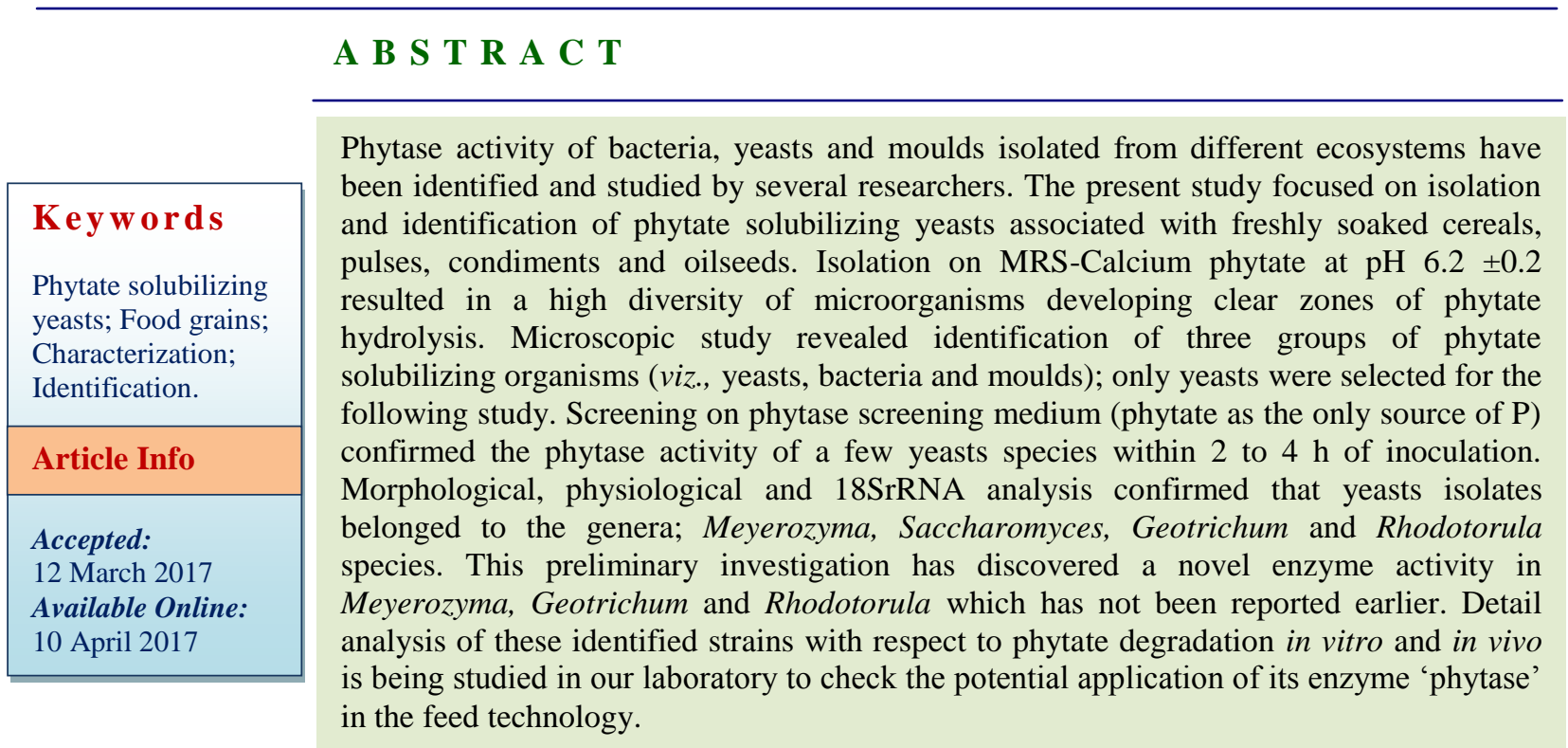

\section{Introduction}

Phytic acid is a complex organic compound originating in the plant system. It is the major storage form of phosphorus and other nutrients in plants. Phytate (myo-inositol hexakisphosphate) is formed naturally during maturation of plants and their seeds. Its content is quite high in cereals, oilseeds, condiments and nuts. Earlier several scientists isolated phytate from plants and seeds in the form of a 'globoid' and confirmed its main chemical contents to be carbon, phosphorus and metal ions. Winterstein (1897) named these globoids as inositol-phosphoric acid. Its chemical nature was later studied in detail and the name was revised as 'myo-inositol (1, 2, 3, 4, 5 and 6) hexakis-dihydrogen phosphate' by IUPAC-IUB (1968). Phytic acid is considered as an anti-nutritional factor of plant based foods. It is not digestible by human beings and non-ruminant animals as their digestive system lacks the enzyme to solubilize them.

Hydrolysis of phytic acid is important in the human diet, especially to vegetarians. Phytase (myo-inositol hexakisphosphate phosphor hydrolases) is special class of enzyme 
specifically hydrolyzing highly stable phytic acid (phytate), releasing free myo-inositol phosphates and minerals. Phytase is widespread in nature. It is occurring in every plant system, dry seeds and selected animal tissues.

Phytase activity is prevalent in microorganisms. Since the understanding of the significant role of enzyme phytase, industrial development in food and feed processing has created a potential of over $\$ 500$ million market, mainly as feed additive in poultry farming (Mullaney et al., 2000). During the last 50 years, research has led to an increased use of phytase supplemented soybean and corn meal along with other plant materials as protein and mineral sources in animal feeds.

Phytase activity has quite frequently been detected in fungi. Various species of yeasts and moulds have been identified to produce good extracellular enzyme activity. Strains of Aspergillus ficuum and A. niger have already been employed for industrial purposes. Other moulds like Mucor piriformis and Rhizopus oligosporus are also known to produce phytase (Bogar et al., 2003a).

Yeasts are commonly found in the surrounding environment and are the common inhabitants of food as well as gastrointestinal tract of animals and human beings. Several yeast strains are known to produce this enzyme. Phytase activity has been detected in Schwanniomyces occidentalis, Pichia anomala and few Saccharomyces species (Nakamura et al., 2000). According to Shamna et al., (2012) since phytate in the small intestine negatively affects absorption of minerals like $\mathrm{Zn}, \mathrm{Ca}, \mathrm{Mg}$ and $\mathrm{Fe}$ and reduce digestibility of dietary proteins, using certain yeast species as probiotics would probably help to overcome negative effects of plant phytates. These probiotic yeasts can possibly be found occurring naturally in our daily food. Hence the main objective of this study was to isolate and characterize phytate solubilizing yeasts from different food grains like cereals, oilseeds, pulses and condiments. This would represent the significance of yeasts microbiota naturally present in food grains. Native yeast plays an important role in natural fermentation of sprouted grains and grain-flours.

\section{Materials and Methods}

\section{Isolation of phytate solubilizing yeasts}

Selected grains/seeds of cereals, pulses, condiments, oilseeds were soaked for $2 \mathrm{~h}$ in sterile water and isolations were carried out by standard plate count method. Food yeasts are fast growing common contaminants in the MRS medium (De Man et al., 1960) which is used to isolate lactic acid bacteria from foods. Hence this medium was utilized to isolate yeasts from soaked grains/seeds. Potassium orthophosphate from MRS medium was eliminated, and $0.5 \%$ calcium phytate (Organic source- phytic acid calcium salt, HiMedia) was used as a substrate for the induction of phytase. Only zone forming colonies were picked up and purified by streak plate method using MRS medium (devoid of dipotassium orthophosphate). Pure cultures, both bacteria and yeasts were preserved in $15 \%$ glycerol (at $-20^{\circ} \mathrm{C}$ ) for further study. Only phytate solubilizing yeasts strains were considered for the following investigation and were coded as 1 to 13 (Table 1).

\section{Characterization of phytate solubilizing yeasts}

\section{Morphological study}

All the phytate degrading yeasts isolates were stained with lactophenol cotton blue (HiMedia) and observed under microscope at 
40X and 100X magnifications. Morphological characters like colony type, cell shape, cell arrangement cell arrangement, size and budding nature was recorded by simple staining, without heat fixing. Yeast isolate selected as positive for solubilization of calcium phytate in MRS medium were characterized and tentatively identified as described by Deak and Beuchat (1996) and Van der Walt and Yarrow (1984). Each isolate was given group code as $\mathrm{M}, \mathrm{S}, \mathrm{G}$ and $\mathrm{R}$ (Table 2) and strains were coded as 1 to 13.

\section{Physiological study}

Phytate solubilizing yeast isolates were screened for the enzyme activity viz., amylase, caseinase, gelatinase and hemolytic activity by culturing them on starch agar (Harrigan and McCance, 1979), skim milk agar (Chalmers, 1962), gelatine medium (Smith et al., 1952) and sheep blood agar (Mata et al., 1969) respectively. Reference organism Saccharomyces cerevisiae positive for starch hydrolysis was inoculated in one section and phytate solubilizing yeast on the other half section of the starch agar plate. Amylase activity was tested by flooding iodine solution on $48 \mathrm{~h}$ incubated starch agar plates. Isolates representing clear zones were recorded as positive (+) and those appearing blue were recorded as negative (-).Casein hydrolysis was tested by observing clearance of white colour (milk) in the skim milk agar plates. Test tubes containing gelatin medium were allowed to solidify in the refrigerator. The medium was inoculated with phytate solubilizing yeasts by stab method and incubated at room temperature $\left(28^{\circ} \mathrm{C}\right)$. Test tubes were transferred in refrigerator for $2 \mathrm{~h}$ to check gelatin hydrolysis after $72 \mathrm{~h}$ of incubation. The test tubes with molten state of gelatin after refrigeration were recorded as positive and those in solidified state were recorded as negative for gelatinase activity. Hemolysis test was carried out by aseptically adding freshly drawn sheep blood into molten
SBA agar medium, mixed thoroughly, poured into the plates and allowed to solidify. The yeasts cultures were streaked on the plates and incubated at $37^{\circ} \mathrm{C}$. Plates were observed for hemolysis of blood (indicated by the halo zone) on SBA medium after $48 \mathrm{~h}$.

In sugar fermentation tests, phytate solubilizing yeasts isolates were inoculated in yeast extract sucrose (YES) broth that contained $20 \%$ sucrose and $2 \%$ yeast extract (Daouk et al., 1995). The cultures were incubated in water bath shakers for $48 \mathrm{~h}$ at $32^{\circ} \mathrm{C}$ to visually inspect froth formation on the surface $\left(\mathrm{CO}_{2}\right.$ production). Later the same cultures were kept still (without shakers) for another $24 \mathrm{~h}$ to check alcohol production. Saccharomyces cerevisiae var., ellipsoideus that ferments sucrose to alcohol with rapid production of $\mathrm{CO}_{2}$ (with accumulation of froth) was used as a reference organism.

\section{Screening of selected isolates}

Screening was carried out to check the growth and confirm phytase activity of the isolates on chemically defined phytase screening agar medium [PSM] (Howson and Davis, 1983). Calcium phytate $(0.5 \%)$ was added to medium as the only source of phosphorus. PSM agar plates were marked into quadrants and loop full of yeast culture was placed directly on four different spots marked in PSM plates. The plates were observed for clear zones every $2 \mathrm{~h}$ and up to $24 \mathrm{~h}$ of incubation (at $32^{\circ} \mathrm{C}$ ). Strains that showed good zone of solubilization within 2- $4 \mathrm{~h}$ were designated as the best strains. From each group one strain was selected for further identification.

\section{Identification of effective phytate solubilizing yeasts by 18SrRNA}

One species from each group of tentatively identified yeasts genera (Table 1) was selected for 18SrRNA analysis. Total genomic DNA from yeast was isolated by N- 
Cetyl- N, N, N-trimethyl- ammonium bromide (CTAB) method. Quantity of the isolated DNA was checked in UV-VIS spectrophotometer (Vivaspec Biophotometer, Germany). From the stock solution, $1 \mu$ DNA was mixed with $49 \mu$ sterile distilled water to get 50 times dilution. The A260/A280 ratio was recorded to check purity of DNA preparation. Polymerase chain reaction (PCR) amplification of internal transcribed spacer (ITS) region was done in $20 \mu$ of reaction mixture. BIOTRON (German make) PCR instrument was used for amplification.

\section{Oligonucleotide primers used:}

\begin{tabular}{|c|c|c|c|c|c|}
\hline Oligonucleotide & Sequence (5'-3’) & $\begin{array}{c}\mathrm{GC} \\
\%\end{array}$ & $\begin{array}{c}\mathrm{T}_{\mathrm{m}} \\
\text { value }\end{array}$ & Length & $\begin{array}{l}\text { Product } \\
\text { size }\end{array}$ \\
\hline $18 \mathrm{~S}$ FP & GCCTGTCTCAAAGATTAAGCC & \multirow[t]{2}{*}{48} & \multirow[t]{2}{*}{52.4} & \multirow[t]{2}{*}{$\mathrm{C} 21$} & \multirow[t]{2}{*}{$700 \mathrm{bp}$} \\
\hline $18 \mathrm{~S}$ RP & CACCTACGGAGACTTTGTTAC & & & & \\
\hline
\end{tabular}

GC: Guanine and cytosine, Tm: melting temperature, FP: forward primers, RP: reverse primers

PCR temperature profile maintained is as follows

\begin{tabular}{|c|c|c|c|}
\hline Process & Temperature & \multicolumn{2}{|l|}{ Time } \\
\hline Initial denaturation & $94^{\circ} \mathrm{C}$ & \multicolumn{2}{|l|}{$2 \mathrm{~min}$} \\
\hline Denaturation & $48^{\circ} \mathrm{C}$ & $50 \mathrm{~s}$ & \\
\hline Annealing & $48^{\circ} \mathrm{C}$ & $30 \mathrm{~s}$ & 30 cycles \\
\hline Extension & $72^{\circ} \mathrm{C}$ & $1 \mathrm{~min} 30 \mathrm{~s}$ & \\
\hline Final extension & $72^{\circ} \mathrm{C}$ & $6 \mathrm{~min}$ & \\
\hline
\end{tabular}

\section{BLAST analysis}

BLAST program was used for the data submitted to NCBI Gene-Bank database to assess the DNA similarities. Multiple sequence alignment of 18SrRNA sequence was conducted followed by Phylogram using CLUSTALAW multiple sequence alignment tool.

\section{Results and Discussion}

\section{Isolation of phytate solubilizing yeasts}

Yeasts were found to be growing luxuriously in the MRS medium of $\mathrm{pH} 6.2 \pm 0.2$. The visible zones of clearance (Ca- phytate hydrolysis) around the colonies in the MRS isolation plates aided in recognizing phytate degrading yeasts from the other species.

\section{Characterization of phytate solubilizing yeasts}

\section{Morphological study}

The morphology study (Table 1) resulted in presumptive identification of four different species of yeasts viz., Meyerozyma sp., Saccharomyces sp., Rhodotorula sp. and Geotrichum sp.

\section{Physiological study}

Yeasts revealed different enzyme activity other than phytase. Growth was observed in all the media (starch agar, milk agar, gelatin and sheep blood agar), but the strains showed negative test for casein, gelatin and hemoglobin hydrolysis (hemolysis). Most of the yeasts isolated from food grains were positive for starch hydrolysis except one 
strain of Meyerozyma $\left(\mathrm{M}_{3}\right)$ and two strains of Geotrichum $\left(\mathrm{G}_{11}\right.$ and $\left.\mathrm{G}_{12}\right)$. The addition of iodine to starch agar plates inoculated with yeast isolates exhibited wide zone of starch degradation indicating good amylase activity. Phytate solubilizing yeast isolates showed good turbidity in YES medium and population significantly increased within $24 \mathrm{~h}$ of inoculation Group-S (Saccharomyces sp.) and reference organism Saccharomyces cerevisiae var., ellipsoideus produced profuse froth on the surface of the broth which was an indication of rapid $\mathrm{CO}_{2}$ production. It also showed presence of alcohol. However, group$\mathrm{M}$ (Meyerozyma), $\mathrm{G}$ (Geotrichum) and $\mathrm{R}_{13}$ (Rhodotorula) did not produce any froth on the surface of the broth and there was no production of alcohol.

\section{Screening of selected isolates}

PSM screening confirmed the phytase enzyme activity of all the strains selected from the isolation plates. The zone of phytate solubilization was observed in some strains within $4 \mathrm{~h}$ of inoculation in PSM medium (Table 2). These strains were selected for 18SrRNA analysis.

\section{Identification of effective yeast strains by 18SrRNA}

BLAST analysis of the gene sequence (601bp) of phytate solubilizing budding yeast isolate selected from the group- M (Table 1) identified $\mathrm{M}_{4}$ as Meyerozyma guilliermondii with $99 \%$ homology. The gene sequence (610 bp) of oval shaped budding yeasts $S_{8}$ characterized as Saccharomyces was identifed as $S$. cerevisae with $100 \%$ homology. The gene sequence (519 bp) of phytate degrading pseudo-mycelial, white powdery yeast $\mathrm{G}_{12}$ was identified as Geotrichum candidum with 99\% homology. The gene sequence (581bp) of the pink pigmented yeast isolate $\mathrm{R}_{13}$ (Table 1) was identifed as Rhodotorula mucilaginosa with $98 \%$ homology.

Yeasts are always associated with cereals and pulses and are predominantly involved in the fermentation of sprouted-grains (beer production) and grain-flours (idli /dosa batter fermentation). In this study, isolation in MRSPhytate medium resulted in various groups of phytate utilizing yeasts. Phytate solubilizing microorganisms have been isolated from different food sources by researchers on MRS medium enriched with phytate as it is known to induce phytase activity in the growth medium (Haros et al., 2008 and Raghavendra and Halami, 2009).

Varied colony morphology as well as phytase activity was observed within $24 \mathrm{~h}$ of isolation indicating rich diversity of phytate solubilizing yeasts inhabiting food grains. Phytase activity of yeasts like Saccharomyces sp. isolated from cereal based foods and beers have been reported by Nuobariene et al. (2011). Presence of different groups of native yeasts in food grains and their significant role in fermentation process has been reviewed in detail by Poutanen et al., (2009). Geotrichum candidum is an important yeast in agro food industries in Western countries. It is always found associated with grains, fruits and diary products (Gente et al., 2006). Association of Meyerozyma (earlier referred as Candida), Geotrichum and Rhodotorula with foods has been reported by several researchers (Tamang et al., 2016). 
Table.1 Morphological study of phytate solubilizing yeasts isolated from food grains/seeds

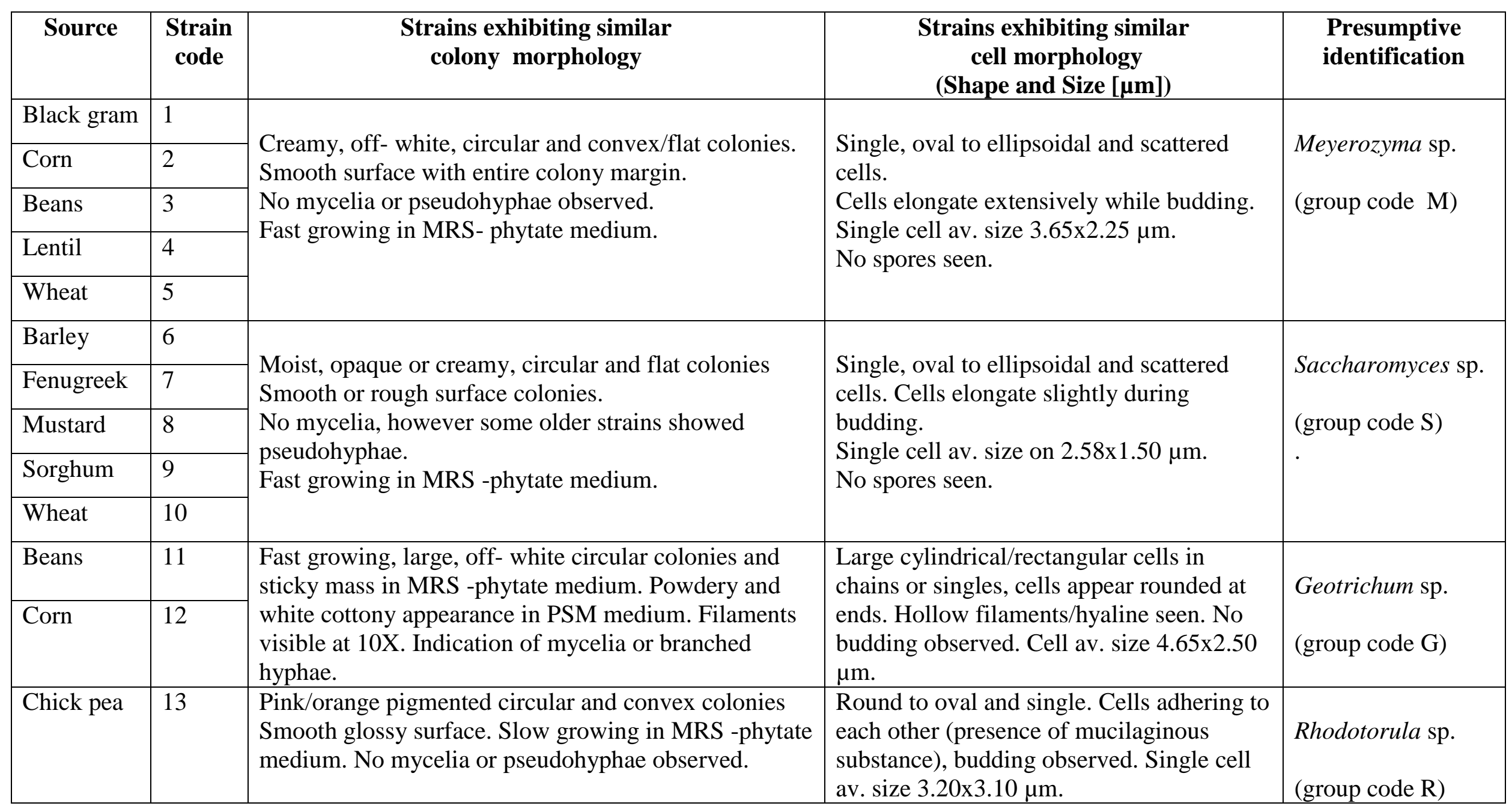


Table.2 Physiological study of phytate solubilizing yeasts isolated from food grains/seeds

\begin{tabular}{|c|c|c|c|c|c|c|c|c|}
\hline \multirow{2}{*}{\multicolumn{2}{|c|}{$\begin{array}{l}\text { Tentatively Identified } \\
\text { groups (with strains } 1 \\
\text { to13) }\end{array}$}} & \multirow{3}{*}{$\begin{array}{l}\text { Starch } \\
\text { Hydrolysis } \\
+\end{array}$} & \multirow{3}{*}{$\begin{array}{l}\text { Casein } \\
\text { Hydrolysis } \\
-\end{array}$} & \multirow{3}{*}{$\begin{array}{l}\text { Gelatine } \\
\text { Hydrolysis } \\
-\end{array}$} & \multirow{3}{*}{$\begin{array}{l}\text { Hemolytic } \\
\text { Activity } \\
\text { - }\end{array}$} & \multicolumn{2}{|c|}{ YES Broth } & \multirow{3}{*}{$\begin{array}{l}\begin{array}{l}\text { Screening } \\
\text { (zones within } \\
\text { hours) }\end{array} \\
6 \mathrm{~h}\end{array}$} \\
\hline & & & & & & \multirow{2}{*}{$\begin{array}{l}\text { Froth } \\
-\end{array}$} & \multirow{2}{*}{$\begin{array}{l}\text { Alcohol } \\
-\end{array}$} & \\
\hline Meyerozyma & $\mathrm{M}_{1}$ & & & & & & & \\
\hline (M) & $\mathrm{M}_{2}$ & + & - & - & - & - & - & $4 \mathrm{~h}$ \\
\hline & $\mathrm{M}_{3}$ & - & - & - & - & - & - & $4 \mathrm{~h}$ \\
\hline & $\mathbf{M}_{4}$ & + & - & - & - & - & - & $2 \mathrm{~h}$ \\
\hline & $\mathrm{M}_{5}$ & + & - & - & - & - & - & $4 \mathrm{~h}$ \\
\hline \multirow{5}{*}{$\begin{array}{l}\text { Saccharomyces } \\
\text { (S) }\end{array}$} & $\mathrm{S}_{6}$ & + & - & - & - & + & + & $8 \mathrm{~h}$ \\
\hline & $\mathrm{S}_{7}$ & + & - & - & - & + & + & $8 \mathrm{~h}$ \\
\hline & $\mathbf{S}_{8}$ & + & - & - & - & + & + & $4 \mathrm{~h}$ \\
\hline & $\mathrm{S}_{9}$ & + & - & - & - & + & + & $6 \mathrm{~h}$ \\
\hline & $\mathrm{S}_{10}$ & + & - & - & - & + & + & $8 \mathrm{~h}$ \\
\hline \multirow{2}{*}{$\begin{array}{l}\text { Geotrichum } \\
\text { (G) }\end{array}$} & $\mathrm{G}_{11}$ & - & - & - & - & - & - & $2 \mathrm{~h}$ \\
\hline & $\mathbf{G}_{12}$ & - & - & - & - & - & - & $2 \mathrm{~h}$ \\
\hline Rhodotorula (R) & $\mathrm{R}_{13}$ & + & - & - & - & - & - & $8 \mathrm{~h}$ \\
\hline
\end{tabular}

Note: Numericals indicate phytate solubilizing strains isolated from soaked grains. PSM screening observations recorded every $2 \mathrm{~h}$ and upto $24 \mathrm{~h}$. YES broth-Yeast extract sucrose; PSM-Phytase screenng medium. Highlighted strains indicate efficient phytate solubilizing yeast in each group.

However their phytase activity has not been so far reported by any investigators. Thus, the study reveals the novel enzyme activity of yeasts associated with food grains. Saccharomyces sp. isolated from sprouts or soaked grains are well studied for their amylase activity. Hence, they find an effective application in fermentation of cereals. Most of the yeasts studied have led to negative results for casienase and gelatinase activities. Negative results for hemolysis indicated that organisms do not lyse red blood cells, hence could be considered as nonpathogenic. Strains displaying accumulation of lather (rapid $\mathrm{CO}_{2}$ production) on the surface of YES broth with alcohol production were considered as Saccharomyces sp. as these characteristics are commonly observed in S. cerevisiae (Deak and Beuchat, 1996). Screening on phytase screening medium (PSM) revealed the effectiveness of the yeast strains in hydrolyzing calcium phytate within
2-4 h. Screening by PSM plate assay has been characteristically used to screen phytate solubilizing microorganisms (Sreedevi and Reddy, 2012). PSM is chemically defined minimal nutrient medium with phytate (organic compound) as the only source of P. It was observed that PSM did not support vigorous growth of yeasts cells but induced phytase activity, displaying maximum diffusion ability of the enzyme phytase within $24 \mathrm{~h}$. This was probably due to minimum nutrients accessibility. It is a known fact that cells under P- stress induce phytase activity in the presence of phytate and absence of inorganic P source (Kim et al., 1999).

Strain $\mathrm{M}_{4}$ identified as Meyerozyma guilliermondii, $\mathrm{G}_{12}$ identified as Geotrichum candidum and $\mathrm{S}_{8}$ identified as Saccharomyces cerevisiae by 18 SrRNA analysis were selected as competent phytate solubilizing yeast for further study. The pink pigmented 
strain $\mathrm{R}_{13}$ identified as Rhodotorula mucilaginosa was not considered as the strain was slow growing and showed delayed zone of phytate solubilization. Detail analysis of these identified strains with respect to phytate solubilization/degradation in vitro and in vivo is being studied in our laboratory to check the potential application of its enzyme 'phytase' in the feed technology.

\section{References}

Bogar, B., Szakacs, G. Linden, J.C., Pandey, A. and Tengerdy, R.P. 2003a. Optimization of phytase production by solid substrate fermentation. J. Ind. Microbiol. Biotechnol., 30: 183-189.

Chalmers, C.H. 1962. Bacteria in Relation to the Milk Supply. $4^{\text {th }}$ Edition, Edward Arnold publishers Ltd., London, UK. pp. 291.

Daouk, R.K., Dagher, S.M. and Sattout E.J., 1995, Antifungal Activity of the Essential Oil of Origanum syriacum L.. J. Food Protection, 58(10): 1147-1149.

De Man, J.C., Rogosa, M. and Sharpe, M. E., 1960, A Medium for the Cultivation of Lactobacilli. J. Appl. Bacteriol., 23: 130-135.

Deak, T. and Beuchat, L.R. 1996. Handbook of food spoilage yeasts. Boca Raton, FL: CRC Press.

Gente, S., Sohier, D., Coton, E., Duhamel, C. and Guéguen, M. 2006. Identification of Geotrichum candidum at the species and strain level: Proposal for a Standardized Protocol. J. Industr. Microbiol. Biotechnol., 33: 1019-1031.

Haros, M., Bielecka, M., Honke, J. and Sanz, Y., 2008, Phytate Degrading Activity in Lactic Acid Bacteria. Pol. J. Food Nutr. Sci., 58: 33-40

Harrigan, W.F. and McCance, E.M. 1979. The Microbiological Examination of Foods. In: Laboratory Methods in
Microbiology, $3^{\text {rd }}$ Ed., Academic Press, London and New York.

Howson, S.J. and Davis, R.J. 1983. Production of Phytate Hydrolysing Enzyme by Fungi. Enzyme Microbiol. Technol., 5: 377-382.

IUPAC-IUB. 1968. The nomenclature of cyclitols: Tentative rules. Euro. J. Biochem., 5: 1-12.

Kim, D.H., Oh, B.C., Choi, W.C., Lee, J.K. and Oh, T.K. 1999. Enzymatic Evaluation of Bacillus amyloliquefaciens, Phytase as a Feed Additive. Biotech. Lett., 21: 925-927.

Mata, L.J., Carrillo, C. and Villatoro, E. 1969. Fecal Microflora in Healthy Persons in a Preindustrial Region. Appl. Microbiol., 17: 596-602.

Mullaney, E.J., Daly, C.B. and Ullah, A.H. 2000, Advances in Phytase Research. Adv. Appl. Microbiol., 47: 157-199.

Nakamura, Y., Fukuhara, H. and Sano, K. 2000. Secreted phytase activities of yeasts. Biosci. Biotechnol. Biochem., 64(4): 841-844.

Nuobariene, L., Hansen, A.S., Jespersen, L. and Arneborg, N. 2011. Phytase Active Yeasts from Grain Based Food and Beer. J. Appl. Microbiol., 110: 13701380.

Poutanen, K., Flander, L. and Katina, K. 2009. Sourdough and cereal fermentation in a nutritional perspective. Food Microbiol., 26: 693699.

Raghavendra, P. and Halami, P.M. 2009, Screening, selection and characterization of phytic acid degrading lactic acid bacteria from chicken intestine. Int. J. Food Microbiol., 133:129-134.

Shamna, K.S., Rajamanikandan, K.C., Mukesh Kumar, D.J., Balakumaran, M.D. and Kalaichelvan, P.T. 2012. Extracellular Production of Phytases by 
a Native Bacillus subtilis Strain. Ann. Biol. Res., 3: 979-987.

Smith, N.R., Gordon, R.E. and Clark, F.E. 1952. Aerobic Spore Forming Bacteria. In: Agril. Monograph. United States Department of Agriculture, Washington DC. pp 148.

Sreedevi, S. and Reddy, B.N. 2012. Isolation, Screening and Optimization of Phytase Production from Newly Isolated Bacillus sp. C 43. Int. J. Pharm. Biol. Sci., 2: 218-231.

Tamang, J.P., Watanabe, K. and Holzapfel, W.H. 2016. Review: Diversity of
Microorganisms in Global Fermented Foods and Beverages. Front. Microbiol., 7: Article-377.

Van der walt, J.P., and Yarrow, D. 1984. Methods for the isolation, maintenance, classification and identification of yeasts. In: N.J.W. Kreger-van Rij, The yeasts: A Taxonomic Study, pp. 45 \& 105.

Winterstein, E. 1897. A Phosphorus Compound from Plants, Which Yields Inosite on Decomposition. Ber. Dtsch. Chem. Ges., 30: 2299-2302.

\section{How to cite this article:}

Savita, P.D., V.C. Suvarna, T. Annu, A.N. Balakrishna, B. Kanchanashri and Yallappa, M. 2017. Isolation, Characterization and Identification of Phytate Solubilizing Yeasts Dwelling Food Grains. Int.J.Curr.Microbiol.App.Sci. 6(4): 1184-1192. doi: https://doi.org/10.20546/ijcmas.2017.604.145 